\title{
ANARQUIA EM SICÍLIA — UMA REVOLTA DE ESCRAVOS NA SIRACUSA ANTIGA 491/490 A.C.
}

\author{
MORITZ HERRMANN*
}

Resumo: No ano 491 ou 490 a.C. o demos de Siracusa, uma das principais cidades gregas na parte oriental da ilha de Sicília, se alia aos kyllyrioi, uma população agrária escravizada, expulsando a aristocracia escravocrata e latifundiária dos gamoroi da cidade. Segue-se o que Aristóteles chama de um estado de anarquia, que é somente terminado com a ascensão da tirania de Gelão, que cria uma nova ordem política em Siracusa. Este artigo pretende examinar a relevância da análise de classes para o entendimento destes eventos, ponderando assim também a relevância da categoria para a história da antiguidade em geral. Adicionalmente, se tenciona mostrar, como classe e trabalho na Sicília antiga estavam vinculados a relações espaciais, criando assim uma situação de fronteira que moldou a forma das lutas políticosociais sicilianas no 5 o século a.C.

Palavras-chave: Sicília. Escravidão. Luta de classes. Grécia Antiga.

\section{Anarchy in Sicily - a slave revolt in Ancient Syracuse 491/490 BC}

Abstract: In the year 491 or 490 BC the demos of Syracuse, one of the major Greek cities of oriental Sicily, forms an alliance with the kyllyrioi, an enslaved agrarian population, and expels their masters, the landowning aristocracy called the gamoroi. It follows what Aristoteles considers a state of anarchy that is only terminated by the rise of the tyranny of Gelon, which creates a new political order in Syracuse. This article pretends to examine the relevance of class analysis for the understanding of these events, thereby also considering the relevance of the category of class for ancient history in general. Additionally it is attempted to demonstrate, how class and labor in ancient Sicily were interconnected with spatial relationships, creating a frontier situation that shaped the form of Sicilian sociopolitical struggle in the fifth century BC. Keywords: Sicily. Slavery. Class-struggle. Ancient Greece.

Introdução: o problema de classe na antiguidade e na historiografia contemporânea

No ano 491 ou 490 a.C. o demos de Siracusa, uma das principais cidades gregas na parte oriental da ilha de Sicília, se alia aos kyllyrioi, uma população agrária escravizada, expulsando a aristocracia escravocrata e latifundiária dos gamoroi da cidade. Segue-se o que Aristóteles chama de um estado de anarquia, que é somente terminado com a ascensão da tirania de Gelão, que cria uma nova ordem política em Siracusa. Este artigo pretende examinar a relevância da análise de classes para o entendimento destes eventos, ponderando assim também a relevância da categoria

\footnotetext{
Doutorando em História na Johannes Gutenberg Universität Mainz (Alemanha). E-mail: moritz.p.herrmann@gmail.com
} 
para a história da antiguidade em geral. Adicionalmente se tenciona mostrar, como classe e trabalho na Sicília antiga estavam vinculados a relações espaciais, criando assim uma situação de fronteira que moldou a forma das lutas político-sociais sicilianas no 5 o século a.C.

Classe é geralmente entendida como uma estratificação social por posicionamentos diferenciados no processo de produção e reprodução da sociedade, ou seja, a forma como o trabalho é organizado. Este posicionamento não é simplesmente uma diferenciação funcional, mas implica interesses desiguais, relações de poder e mais importante ainda, uma relação de exploração entre as classes dominantes e as classes dominadas, a última se apropriando da força de trabalho da outra. Sociedades de classes deste modo mostram uma contradição interna, uma tensão latente, que se expressa em conflitos, chamados de lutas de classe, fatores, segundo a historiografia marxista, considerados essenciais para as dinâmicas históricas das sociedades por seu potencial de se tornarem revolucionários (Ste. Croix, 1981, p. 32-49).

Contudo esta forma de entender o passado foi muitas vezes contestada. A maneira como olhamos para o passado, com quais fins e quais métodos, é influenciado por condições históricas específicas e tem a sua própria historicidade. No discurso historiográfico sobre a antiguidade e o conceito de classe, isto se mostra com muita clareza, especialmente na historiografia produzida na Alemanha. A sociologia da Alemanha ocidental, do estado que ascendeu vitorioso da Guerra Fria e que se entendia como uma sociedade de classe média nivelada, aboliu o termo classe cinco vezes (Steiner, 2008, p. 776-786). Para a Alemanha oriental, que se proclamou um estado de trabalhadores e camponeses, obviamente classe era uma categoria central. Diferenças políticas e ideológicas como estas tornaram a historiografia um outro campo da Guerra Fria e a história da antiguidade não era uma exceção. Nem o anticomunismo fervente de um lado, nem o fato que as "doutrinas de Marx e Engels" se tornavam a base de legitimação de um sistema político, fazendo delas um padrão inquestionável para todas as questões, contribuiu para a qualidade deste debate. Por exemplo, por parte da Alemanha oriental e dos estados do Tratado de Varsóvia o dogmatismo não permitiu o reconhecimento do fato que os textos de Marx e Engels, que se tratam da escravidão antiga, não foram escritos com intenção historiográfica. 
Eram intervenções políticas, que devem ser intendidas no contexto do discurso abolicionista do século XIX. Eles não podem ser aplicados para o estudo da antiguidade de maneira rigorosa sem equívoco (Brockmeyer, 1987, p. 43-69; Nippel, 2005, p. 381). No oeste, com exceção dos historiadores explicitamente marxistas (Starr, 1977, p. 200), o discurso tinha a tendência de cair no outro extremo de negar a aplicabilidade do conceito de classe, muitas vezes aparentemente com a intenção de não ser associado com o marxismo (Harris, 1988, p. 602).

Os argumentos contra o uso da categoria da classe frequentemente parecem se referir a uma versão extremamente simplificada do conceito, presumindo, por exemplo, que sempre existiam somente duas classes, que a classe ignorava diferenças de direitos (Alföldy, 2011, p. 200-201) ${ }^{1}$, que ela não podia diferenciar entre trabalho servil e assalariado (Finley, 1977a , p. 48; Ste. Croix, 1981, p. 58-59), e ultimamente que classes seriam como definição unidades políticas, com suas próprias organizações e uma consciência comum (Brockmeyer, 1987, p. 14; Harris, 1988, p. 598). No entanto, se entendemos classe principalmente como uma relação de exploração, que pode historicamente tomar as mais diversas formas, nem uma destas afirmações parece necessária. Também existe a noção, que devemos descrever o passado exclusivamente em seus próprios termos (Harris, 1988, p. 598; Ste. Croix, 1981, p. 34-35), criando, porém, vários problemas metodológicos, ligados, por exemplo, ao fato que os conceitos do passado não são diretamente acessíveis para o presente, mas só podem ser reconstruídas de maneira teórica. Não é, portanto, possível de subtrair o presente da razão histórica, e não existe um acesso ao passado que não seja mediado por teoria. Quando baseamos esta teoria exclusivamente na tradição, pretensamente sem conceitos analíticos contemporâneos, arriscamos de sermos confinados a perspectiva das classes dominantes que criaram as fontes, especialmente em contextos onde os

\footnotetext{
${ }^{1}$ Geza Alföldy faz esta crítica em relação à antiguidade Romana. Em vez de classes ele apresenta um modelo de estratos e estamentos, mas não consegue mostrar que este modelo teria uma vantagem analítica em comparação com um modelo de classes. $O$ único argumento seria que a sociedade romana não foi estratificada somente em termos econômicos, um fato que é claramente induvidoso. $\mathrm{O}$ argumento implícito é que um modelo é melhor quando ele inclui mais eixos de estratificação social. Se isto for o caso, está incompreensível, contudo porque o autor inclui estamentos e estratos, mas não idade, gênero ou etnicidade, sem dúvida, outras dimensões de estratificação social significantes. A complexidade de uma sociedade obviamente não cabe em um esquema de duas dimensões. Em contrário deste argumento considero que a potência da análise de classes não é exatamente uma sociologia de diversidade social, mas uma ótica que ilumina aspetos centrais das relações socioeconômicas que, entretanto tem um valor analítico como ferramenta entre outras (Ellmers, 2009: 37-60).
} 
dominados foram historicamente mudos (Doi, 1988, p. 5-6). Independente disso, Ste. Croix mostrou de maneira convincente que o conceito de classe é compatível com os termos que, por exemplo, Aristóteles usou para descrever a sua realidade, mostrando assim que o uso do conceito não pode ser considerado um anacronismo (Ste. Croix, 1981, p. 69-79). Isto, porém, não significa que o problema do anacronismo na análise de classe não exista, ele surge especialmente quando os seus termos são usados de maneira abstrata e a-histórica, por exemplo, quando se pergunta quem foram os "capitalistas" na antiguidade. Em vez disto, é necessário desenvolver a análise a partir de contextos históricos concretos, percebendo a especificidade e historicidade das respectivas relações de classe e dos respectivos modos de produção. ${ }^{2}$

Como alternativa ao conceito de classe regularmente aparece o conceito do stand (estamento ou ordo) como foi elaborado por Max Weber, se referindo a um conceito de estratificação a partir de honra ou prestígio social, destacando fatores como descendência, estilo de vida e privilégios. No entanto, não existe necessidade de se decidir entre classe ou estamento uma vez por todas. Ambos podem ou não podem ser aspectos importantes de uma análise e frequentemente estarão vinculados, como já foi teorizado pelo próprio Max Weber (Weber, 1980, p. 177-180). A hegemonia de uma análise marxista, que se apoia exclusivamente na categoria de classe, já está quebrada há muito tempo por pesquisadoras feministas e antirracistas. A questão, como se coloca depois da guerra fria, não é se classe é o fator principal da história, mas sim, se o conceito como ferramenta entre outras pode ser aplicado de maneira iluminante para compreender os processos históricos da antiguidade. Demonstrar isto em relação ao problema dos kyllyrioi e da anarquia em Siracusa é o meu objetivo.

\section{A sociedade de classes na Grécia e Sicília grega}

Nas condições de forças produtivas pouco desenvolvidas, como se apresentam na antiguidade, a maioria do trabalho exercido durante um dia servia principalmente para a subsistência e reprodução. A liberdade aristocrática que envolvia a possibilidade

\footnotetext{
${ }^{2}$ Um exemplo para isto é crença na existência de uma classe de comerciantes "capitalistas" na antiguidade grega criticada por Ste. Croix (Ste. Croix, 1981: 41). O historiador Soviético Frolov atribui uma importância a esta suposta classe para eventos de 491/490 em Siracusa, sem mostrar qualquer evidencia (Frolov, 1995: 84).
} 
de se preocupar extensivamente com negócios políticos, religiosos, artísticos ou intelectuais, dependia da capacidade de se apropriar do trabalho de outros, se elevando desta maneira sobre necessidades básicas. Assim no mundo grego estas atividades foram privilégio de uma minoria, que por instituições como a escravidão ou a concentração da posse da terra, foi capaz de extrair um sobreproduto de um grupo de dominados, ou seja, se apropriar de trabalhos e produtos de trabalho de outros que eram forçados a trabalhar mais do que precisavam para o seu próprio sustento. Assim grande parte do que conhecemos e admiramos da famosa cultura grega, seja poesia, prosa ou filosofia, era de uma ou outra forma dependente de dominação e exploração e limitada a uma classe específica: a aristocracia (Ste. Croix, 1981, p. 32-37).

A possibilidade da exploração exige vários fatores: Ela necessita de uma ideologia que legitima e estabiliza a posição elevada das classes dominantes, no nosso caso, por exemplo, os mitos da descendência divina dos aristocratas ou a teoria da escravidão natural de Aristóteles. Aspectos como prestígio social e práticas culturais de distinção assim podem ampliar a análise de classe (Ste. Croix, 1981, p. 409-417; Berger, 1992, p. 63). Adicionalmente se precisa de um conjunto de leis ou costumes que dão à exploração um caráter sistemático e regulado, o que diferencia a exploração do simples roubo. A escravidão, por exemplo, exige que exista o status legal do escravo e a posse particular da terra também não é uma constante humana, mas é regularmente resultado de conquista que é depois institucionalizada por normas legais (Ste. Croix, 1981, p. 42). Adicionalmente, conhecer e interpretar as leis, muitas vezes consideradas sagradas, tipicamente foi um privilégio das classes dominantes. Assim questões de leis e costumes também são outro aspecto da análise de classes. Finalmente é necessário um poder organizado que seja capaz de impor as normas e leis da classe dominante sobre o resto da comunidade. Propriedade vale pouco, se não pode ser garantida, e privilégios regularmente deixam de ser privilégios se podem ser desrespeitados sem consequência. Isto significa que relações políticas e formas de governo não podem ser omitidas na análise. Por exemplo, a democracia que garante a participação do povo no processo legislativo impedia a arbitrariedade dos aristocratas que muitas vezes usavam seus poderes em governos oligárquicos para expropriar e explorar diversas partes da população livre (Ste. Croix, 1981, p. 17, 63).

Quais classes podem então ser distinguidas no mundo grego antigo e na Sicília 
grega em particular? Como já foi elaborado, a classe dominante aristocrata se definia pela sua extensa posse de terra e seu controle sobre trabalho forçado. Ela também podia agir como arrendadora de terra ou como possuidora de bens de investimento, como navios ou casas de renda ou até como comerciante. Mas a posse de terra era primária e tinha um caráter de prestígio que outras atividades econômicas, especialmente mercantis, careciam. O significado da terra era tão importante que quem fazia uma fortuna em outras áreas, vistas como moralmente inferiores, geralmente procurou se tornar um proprietário de terra. A produção controlada por esta classe servia primariamente para garantir a ela um consumo socialmente adequado, ela não foi conduzida para garantir lucro no sentido de um valor que seja reinvestido para se ampliar (Kippenberg, 1977, p. 17f; Berger, 1992, p. 72). Se os membros da classe dominante trabalhavam pessoalmente, isto nunca era por necessidade, mas como exercício físico. A estima de seu lazer, garantido pela exploração, e das atividades políticas e culturais possibilitadas por este, foram um aspecto central da consciência ideológica desta classe de pertencer aos intrinsecamente "melhores" da sociedade. Como os seus recursos the possibilitaram se armar e treinar em negócios militares, esta classe também tinha uma função central na guerra (Ste. Croix, 1981, p. 114-132). Na Sicília grega, a classe dominante se formou pelos descendentes de colonos gregos, que conquistaram e dividiram a terra entre eles. Em Siracusa os membros desta classe se denominavam gamoroi e conseguiram monopolizar e defender os direitos políticos por um tempo prolongado (Berger, 1992, p. 62).

Em segundo lugar se pode distinguir a classe explorada, que não podia dispor dos seus próprios frutos de trabalho. Esta classe era composta primariamente por escravos, que eram considerados propriedades dos seus senhores. Os escravos ocupavam uma grande variedade de funções e posições econômicas e sociais que também eram entre si hierarquizadas, por exemplo, pelo dever de observar e disciplinar outros escravos. Em geral, os escravos eram um grupo heterogêneo sem organização coletiva e a rebeldia aberta era relativamente rara na antiguidade (Ste. Croix, 1981, p. 140-147). Por isto e por uma suposta falta de consciência de classe muitas vezes os escravos não foram considerados uma classe de modo algum. Porém, a consciência de uma classe historicamente muda é difícil de estudar, e afirmações com 
esta base tem uma tendência especulativa. Finalmente, consciência de classe não é um requisito de classe, mas sim aspecto de um processo de organização política a partir da classe (Marx, 1972, p. 181; Ste. Croix, 1981, p. 59-62). Impossibilitar um processo de articulação coletiva era uma das principais preocupações dos donos de escravos, que mostravam uma consciência de classe muito clara: Temendo revoltas eles se fraternizavam contra seus escravos em proteção mútua (Ste. Croix, 1981, p. 147) e compravam os seus escravos com o critério de serem estrangeiros de culturas e etnicidades diversas para dificultar que eles se unissem (Aristóteles, Politeía 1220a) ${ }^{3}$. Mesmo com a falta de qualquer liberdade de fala ou reunião, podemos dizer que existia uma constante luta de classes dos escravos, que era, porém, oculta, se exprimia, por exemplo, na suposta "estupidez" dos escravos que "esqueciam" ordens ou trabalhavam lentamente (Ste. Croix, 1981, p. 66).

Pelo fato de a escravidão de barbaroi (pessoas não gregas) ser vista como algo preferencial pela sua suposta inferioridade natural em comparação com gregos, a escravidão também tinha uma dimensão étnica (Herrmann-Otto, 2009, p. 19-20; Maezawa, 1988, p. 16). Este etnocentrismo gerou uma situação peculiar no contexto da colonização grega que criou póleis ao lado (e regularmente ao custo) de populações vizinhas que eram vistas como predestinados à escravidão, transformando assim a fronteira da colonização em uma fronteira de exploração potencial.

A exploração dos descendentes da população nativa, porém, tinha formas especiais. Entre a totalidade dos escravos existia um grupo particular e relativamente incomum na época, que representava um status médio entre liberdade e plena escravidão. Este grupo de "escravos coletivos" ou "escravos de estado" (Brockmeyer, 1987, p. 133), que vou denominar de servos pela falta de uma única palavra original, era forçado a permanecer em um pedaço de terra e obrigado a ceder uma parte da sua produção ao seu dono. Isto significa que estas pessoas tinham a possibilidade de ter uma vida relativamente autônoma e podiam ter as suas próprias famílias sem medo de serem separados pela venda no mercado de escravos. Tal servidão muitas vezes se originou na sujeição de uma população local sobre a polis, especialmente em um

\footnotetext{
${ }^{3}$ Para a conveniência do leitor todos os textos antigos neste trabalho serão citados não pela página na edição usada, mas pelo padrão de citação internacionalmente estandardizado da respectiva obra. Isto possibilita facilmente encontrar as passagens citadas mesmo usando edições divergentes.
} 
contexto de colonização. Os heílotai, os servos de Esparta, são o exemplo melhor conhecido por esta forma de escravidão e são assim também mencionadas nas fontes para explicar o status dos kyllyrioi de Siracusa (Aristóteles, Fragmento 586 Rose; Frolov, 1995, p. 78). Entre os heílotai, aqueles de Messena mostravam uma tendência de insurreição especialmente grande, exigindo dos Espartanos vigilância permanente. Esta tendência é explicada por sua relativa homogeneidade como grupo, o apoio de compatriotas livres e pela sua relativa autonomia em relação a outros escravos. Os kyllyrioi, descendentes de uma população anterior à colonização grega, aparentemente tinham traços similares (Herrmann-Otto, 2009, p. 61-69; Ando, 1988; Ste. Croix, 1981, p. 135-139, 148-157). A fronteira da exploração, porém, não era uma fronteira simplesmente entre escravos e livres. Existiam, por exemplo, grupos de livres entre os explorados que exerciam trabalho assalariado como diaristas. Este grupo era portanto numericamente marginal na população total (Ste. Croix, 1981, p. 113, 505).

Se chamamos a Grécia antiga de uma sociedade escravista, isto significa que a maior parte da riqueza das classes dominantes, que lhes permitiu tomar o seu lugar de dirigente na sociedade inteira, era resultado da sua exploração de trabalho forçado. Isto, porém, não significa que a maioria da população total seria escrava ou dona de escravos (Ste. Croix, 1981, p. 52-55). Existia uma vasta classe média composta por pessoas livres que não tinha acesso à posse de terra ou só de maneira limitada e que não possuía escravos ou se possuía não podia exclusivamente viver do trabalho deles. Esta classe média formada por pequenos agricultores, artesãos e metecos, não era exploradora de trabalho da mesma forma que a classe dominante e corria o risco de também ser explorada, por exemplo, por impostos ou trabalho forçado. É este grupo, que mesmo sendo majoritário não formou a nossa visão da antiguidade, a que referimos, quando se fala do demos no sentido mais restrito dos "pobres" ou do "povo comum". A classe média tinha os seus próprios interesses e podia entrar em conflito, mas também em aliança com as outras classes (Berger, 1992, p. 62-64; Ste. Croix, 1981, p. 133). No caso de Siracusa, é provável que a exclusividade da posse de terra e dos direitos políticos dos gamoroi podia ter gerado um conflito entre eles e o demos (Berger, 1992, p. 71). 


\section{O desenvolvimento político-social de Siracusa da colonização até o 50 século a.C.}

Siracusa foi fundada por colonos dóricos da cidade de Corinto no 8o século a.C. A maioria da sua história mais antiga está oculta, mas aparentemente famílias aristocratas tinham um papel importante na fundação da polis (Tucídides 6.3.2). Apesar do elemento aristocrata também participavam outros grupos das áreas rurais da pátria que queriam, após uma perda de status, se reinstituir como donos de terra ou escapar de uma tal queda. Estes primeiros colonos se apropriaram da maior parte das terras e eventualmente formaram a classe latifundiária dos gamoroi. Eles também formaram uma fronteira contra imigrantes posteriores, que foram na sua maioria confinados a terras menos férteis ou atividades urbanas pouco prestigiosas. Os colonos que chegaram mais tarde formaram as bases do demos de Siracusa, ou quer dizer, das classes médias (Frolov, 1995, p. 73-77; Berger, 1992, p. 62-64).

A população nativa da parte oriental de Sicília, um grupo itálico chamado sikeloi, isto é "sículos"^ em grafia portuguesa, formou outra fronteira: A expansão em terras sicilianas somente foi possível ao custo desta população considerada bárbara pelos gregos sicilianos que em contraste passaram a ser chamados sikeliotai ${ }^{5}$. Já o território original da cidade de Siracusa, a ilha de Ortygia, foi tomada dos sikeloi no ano 733 a.C. (Tucídides 6.3.2). A conquista sucessiva das terras férteis ao redor, que criou a vasta chora (área agrária) de Siracusa, significava a submissão da população nativa. Reduzida a um status comparável com os heílotai, esta população era obrigada a permanecer na terra e forçada a prestar certos serviços como também ceder uma parte do seu produto, mas podia continuar a viver em seus conjuntos familiares (Dunbabin, 1948, p. 111; Frolov, 1995, p. 78; Berger, 1992, p. 74-75). A diferença étnica e cultural assim se tornou em uma diferença de classe, como aconteceu nas colonizações gregas na Ásia Menor, destacando também a relação hierárquica entre campo e cidade em comparação à terra-mãe grega (Ste. Croix, 1981, p. 17). Os sículos submissos, aparentemente uma população muito grande, subsequentemente foram conhecidos sobre os nomes de kyllyrioi, kallikyrioi ou killkyrioi (Suda s.V. Kallikyrioi). Significado e

\footnotetext{
${ }^{4}$ Outros grupos nativos da Sicília eram os sikanoi no centro e os elymoi no oeste da ilha. Estes etnônimos são denominações gregas, e não necessariamente devolvem como estes povos se autodenominavam.

${ }^{5}$ Este nome deve ser atribuído à contemporânea denominação grega da ilha: sikelíe ou sikelía (Tucídides 6.2.5).
} 
origem do nome não são inteiramente claros: Ele pode ser original da língua dos sikeloi, se referir a um pedaço de roupa vestido pelos servos (o que não era incomum por um grupo do seu status), ou, segundo Aristóteles, foi conferido pelo fato que eles afugentaram os seus senhores (Frolov, 1995, p. 79).

Em contraste, os sikeloi que não foram submetidos se retraíram para o interior da ilha, sendo confinados a uma periferia que foi progressivamente diminuída pelas conquistas gregas. A pressão que as expansivas cidades gregas exerciam a seus povoados é bem documentada por fontes arqueológicas (Holloway, 2000: 89). Também se observa uma tendência de helenização nas culturas materiais dos povoados dos sikelioi ao redor das cidades gregas, o que envolve a adaptação de uma escrita com base no alfabeto grego e certos padrões de assentamento (Holloway, 2000, p. 86-90). Isto, porém, não significa necessariamente que estes se tornavam gregos, nem na sua autodefinição, nem na visão das cidades gregas. Revoltas armadas como a de Doukétios (ca. 488 a.C. - 440 a.C.), um líder dos sikelioi helenizado que uniu várias tribos contra os gregos, e cuja cidade principal de Palice era um santuário de escravos fugidos (Maniscalco e McConnel, 2003), mostravam que a helenização até então não tinha apagado as fronteiras. Em contrário, a colonização grega e o regime de trabalho instalado pelas classes dominantes geraram duas relações espaciais contraditórias e marcantes: Aquela entre polis e chora, ou cidade e campo, e aquela entre o domínio grego e a periferia das populações nativas como os sikeloi.

O crescimento da população de Siracusa causada pela contínua imigração grega se apresentou como um perigo para a posição dos gamoroi, que reinavam aparentemente na forma de uma oligarquia ${ }^{6}$. As colonizações secundárias de Siracusa, quer dizer, as fundações de outras cidades como Acrai, Casmene ou Camarina (Tucídides 6.5.2-6.5.3), tinham um papel duplo: Por um lado elas aumentaram o poder político da cidade, por outro lado elas serviam como válvula de escapa pelo conflito interno: Se terras podiam ser ganhas em outro lugar isto alivia a pressão colocada nos latifundiários pelos imigrantes (Frolov, 1995, p. 83-85). Este movimento de expansão não podia ser sustentado infinitamente, e mesmo com a expansão Siracusa sofreu várias staseis (guerras civis): 650 a.C. um grupo de aristocratas chamados Myletides,

\footnotetext{
${ }^{6}$ As fontes relatam a dominância dos gamoroi, mas não conhecemos as concretas instituições do regime político que eles lideravam.
} 
que foi vencido em uma luta pelo poder na cidade, tinha que abandonar Siracusa e tomou parte na fundação de Himera (Tucídides 6.5.1). Uma segunda stasis, cuja data exata é disputada, parece ter originada em uma briga de jovens aristocratas por motivos amorosos, provocando um escândalo e subsequente, uma cisão na comunidade das famílias dominantes. É possível que este conflito interno contribuiu para enfraquecer o poder político das classes dominantes antes da crise do ano 491 a.C. (Berger, 1992, p. 35; Frolov, p. 86-88). A guerra que Siracusa perdeu no ano 492 a.C. contra Hippocrates († 491 a.C.), o tirano de Gela, deve ter sido outro fator que, revelando a fraqueza das classes dominantes, contribuiu para a queda iminente dos gamoroi (Heródoto VII, p. 154-155; Frolov, 1992, p. 88).

\section{Anarquia em Siracusa: luta e conciliação}

A tradição não informa muitos detalhes sobre o fim do domínio dos gamoroi, mas os acontecimentos podem ser resumidos da maneira seguinte: No ano 491 ou 490 a.C. os gamoroi foram forçados a se afastar de Siracusa por uma aliança entre o demos e os kyllyrioi. Os refugiados depois se assentaram em Casmene, uma cidade nos limites da área de influência de Siracusa. A cidade, portanto não parece chegar à paz, e uma nova ordem política não consegue se estabelecer. Seguindo Aristoteles a democracia que foi instalada em Siracusa declina em anarquia e desordem (Aristoteles, Politeía, 1302b). Finalmente, após quatro ou cinco anos, Gelão (540 a.C. - 478 a.C.), filho de Deinomenes, tirano de Gela como sucessor de Hippocrates e comandante de um exército significativo de mercenários ${ }^{7}$, lidera a volta dos gamoroi para Siracusa. Sem luta o demos entrega a cidade, e Gelão se estabelece como tirano em Siracusa, fazendo-a governável através do meio do realojamento forçado e iniciando o reino da dinastia de tiranos dos Deinomenides, que se mantinha na cidade por quase duas décadas (Heródoto VII, p. 155-157; Frolov, 1995, p. 88-90; Berger, 1992, p. 35; Vysokij, 2002, p. 250-256; Hofer, 2000, p. 84-89; Berve, 1953, p. 538-541; Dunbabin, 1948, p. 414; Wentker, 1956, p. 32).

Vários aspetos dos acontecimentos não são inteiramente claros e representados

\footnotetext{
${ }^{7}$ Estes mercenários foram depois assentados em Siracusa, criando novos conflitos sociais (Heródoto VII, 156; Diodoro XI, 72.3).
} 
de maneira divergente na literatura: É controverso, se os gamoroi foram chamados por Gelão ou se foram eles que pediram a ajuda do tirano. Da mesma forma não é claro se o demos entregou a cidade, temendo o militar do tirano, ou se ela deu o poder a Gelão para que ele pudesse assumir o papel de um aiysimnetes (árbitro), comparável a Sólon em Atenas, e terminar a stasis que estava agitando a cidade. Finalmente, também não se sabe com certeza, qual foi o destino dos gamoroi e dos kyllyrioi, porque os seus nomes não aparecem mais, quando as fontes falam de eventos posteriores. A interpretação até então dominante de que os kyllyrioi ganharam a liberdade e foram assimilados pelo demos foi recentemente contestada de maneira convincente (Carlà, 2014). Quando percebemos o conflito em uma ótica de classe, podemos não somente discutir a probabilidade de umas das anteriores versões mas também seguir uma questão até agora pouco investigada: O que aconteceu em Siracusa entre a fuga dos gamoroi provocando a queda da primeira democracia de Siracusa.

É bem provável que o conflito inicial já tinha um aspeto de luta de classe: Especialmente o controle da terra que os gamoroi exerciam tinha o potencial de unir os kyllyrioi e o demos contra a aristocracia. Tanto mais que revoluções democráticas que derrubavam oligarquias regularmente traziam consigo a redistribuição de propriedade (Ste. Croix, 1981, p. 288). E mesmo se a questão das terras não foi o aspecto central do conflito é evidente que depor uma oligarquia - o sistema político que mais privilegiava as classes dominantes - sempre tinha um aspeto de classe.

Não se conhece o exato caráter da aliança entre o demos e os servos, mas é evidente que os interesses comuns dos dois grupos devem ter acabado quando alcançavam o seu alvo da expulsão dos gamoroi. Neste contexto é importante verificar quais termos Aristóteles usa para descrever a causa do declínio da democracia em Siracusa e outras cidades (Politeía, 1302b): Apesar de desordem ( $\alpha \dot{\tau} \alpha \xi \dot{i} \alpha)$ Aristóteles fala de anarquia (àvapxía), o que não deve ser entendido como um simples sinônimo de desordem, característica das revoluções, mas algo mais concreto: O uso da palavra por Aristóteles em Politeía 1319b como também a etimologia (Dierse, 1971) sugere que anarquia significa a ausência de controle especialmente sobre escravos, mulheres e crianças. Ou seja, a falta de autoridade patriarcal e dominação de classe, resultando de uma expansão de direitos políticos considerada ilegítima pelo filósofo. É evidente que especialmente o sentido de classe deve ser primário no contexto de Siracusa, onde 
a questão do status dos kyllyrioi, após a queda dos seus senhores, estava completamente incerta. Será que eles, mesmo sendo bárbaros, podiam ser aceitos como livres ou até cidadãos? E se sim, com quais direitos? A quem pertenciam as terras anteriormente possuídas pelos gamoroi, deviam elas ser posse daqueles que as trabalhavam ou deviam elas ser redistribuídas para o benefício do demos? É necessário considerar, que a polis vivia dos seus arredores rurais, Moses Finley e Ste. Croix até consideram a cidade o parasita do campo (Finley, 1977b, p. 205-327; Ste. Croix, 1981, p. 10-14). Se um grupo rural, numericamente dominante até pouco economicamente explorado, de repente ganha a sua liberdade, se põe a questão existencial para a polis, se ou sobre quais condições esta população se encontra disposta a continuar ceder seu sobreproduto à cidade. Como os kyllyrioi já eram obviamente subsistentes com aquela parte da sua produção que os seus donos os deixaram, não se deu mais a necessidade de produzir um sobreproduto. O abastecimento da cidade com produtos agrários estava ameaçado de ser drasticamente escasseado ou, pelo menos, encarecido. Com outras palavras: O demos não podia estar interessado na emancipação dos kyllyrioi e ainda menos na sua apropriação das terras. Apesar disso, é muito provável que existiam pessoas no demos que aspiravam a posição de classe dos gamoroi ou até indivíduos que já tinham esta posição e somente careciam do seu status e dos seus privilégios. Estes deviam ter sido ativamente comprometidos com o reestabelecimento de dominação sobre os antigos servos. Por outro lado, é duvidoso se os kyllyrioi sentiam alguma forma de lealdade pela cidade que até então tinha os explorados e dominados. O seu grande número, a realização da sua força na revolta contra os gamoroi e o seu significado pela agricultura deve ter dificultado remetê-los à sua antiga submissão (Frolov, 1995, p. 90). Mesmo se os kyllyrioi foram aceitos como cidadãos livres, é pouco provável que sobre estas condições uma democracia estável podia se estabelecer. As democracias antigas, como fica especialmente claro a partir das reformas de Clístenes, estavam baseadas no princípio que a política não podia ser organizada a partir de interesses de grupos particulares, mas tinha que se orientar no estado como um todo (Bleicken, 1986, p. 385-398). Este todo deve ter sido impossível de perceber perante tais contradições fundamentais.

Resumindo: depois do afastamento dos gamoroi, Siracusa deve ter sido o lugar de um conflito social, que envolvia o estabelecimento de uma nova dominação de 
classe, respectivamente da defesa contra tal dominação, e a questão do controle sobre o meio de produção principal da época: a terra. O demos aparentemente não era capaz de encerrar este conflito com as suas próprias forças. Quando então nos perguntamos, porque ele cedeu a cidade a Gelão precisamos nos lembrar, que, apesar da luta de classes, também existe colaboração de classe. O tirano tinha os meios de pacificar a cidade, ou seja, reestabelecer a sociedade de classes, e isto era em face da anarquia ultimamente no interesse tanto dos aristocratas como do demos. A reinstalação dos gamoroi sublinhou a vontade de retomar as estruturas anteriores, mas o fato que eles não voltaram ao poder revela que o fim da primeira democracia Siracusana não era uma simples restauração, mas a criação de uma nova ordem política, que mudará profundamente Siracusa em longo prazo.

Uma destas mudanças é a composição da população da cidade. A estrutura de classe de Siracusa em vista, o fato de Gelão ter forçado os ricos das poleis de Euboia e Megara Hyblaea, a população inteira de Kamarina e a metade dos habitantes de Gela, de se assentar em Siracusa, deixando a cidade a maior de Sicília (Berger, 1992, p. 72), tem um sentido duplo. Primeiramente Gelão terminou a homogeneidade das classes dominantes, rompendo com os privilégios tradicionais e criando uma camada da aristocracia que devia a sua posição na cidade diretamente a ele. Assim ele estabilizou a base do seu poder ao custo da influência dos gamoroi. Mas outro aspecto também precisa ser considerado: Como já estabelecido, apesar de terras, o controle sobre trabalho forçado era o que mais caracterizava as classes dominantes. Aquelas famílias aristocratas que Gelão realojou para Siracusa, obviamente redistribuindo as terras, necessariamente traziam com eles os seus escravos e dependentes, fragmentando assim a população rural e reduzindo desta maneira a ameaça da rebeldia dos kyllyrioi. Se, portanto, os últimos não aparecem mais na tradição, em vez de ter se emancipado, parece mais provável, que os kyllyrioi caíram em uma nova servidão e subsequente perderam a sua coerência como grupo, sendo assimilado em uma classe escrava mais ampla e heterogênea. Algo similar - porém no lado das classes dominantes - deve ter acontecido com os gamoroi, que perderam o seu status especial com a ascensão de novas camadas da classe dominante.

Gelão parece no primeiro instante como um tirano que se apoia nas classes dominantes, dirigindo a volta da velha aristocracia e assentando novas pessoas deste 
status. Mas é improvável que o tirano podia se manter na cidade sem ser pelo menos tolerado pelo demos e o fato que ele não reestabeleceu os privilégios dos gamoroi (Hofer, 2000, p. 87) deve ter sido um sinal importante para o resto da população de Siracusa. Em vez de se apoiar somente em uma classe, aparece que Gelão ofereceu um novo compromisso entre as classes médias e dominantes à base da supressão contínua das classes exploradas e desenvolvimento econômico geral (Berve, 1953, p. 541-543). O fato de que o reino da dinastia dos Deinomenides terminou vinte anos mais tarde com a instalação de uma democracia duradoura mostra que Gelão iniciou um processo não intencional, mas, mesmo assim, típico pelas tiranias gregas: A erosão de privilégios e valores tradicionais baseados na descendência à vantagem do princípio da propriedade, uma mobilidade social maior e a aumentada participação do demos nos processos políticos (Berger, 1992, p. 63-64, 109). Assim a tirania mediou os conflitos internos da polis entre as classes médias e dominantes e a democracia, que dependia na exploração dos escravos, podia se estabelecer sem correr risco de outra vez cair em desordem e anarquia.

Assim, não podemos contar a história dos kyllyrioi como uma história de emancipação, como foi feito por Frolov (Frolov, 1995, p. 89). A sua luta de classe, portanto, provocou uma reação poderosa que, para restituir a sociedade de classes, tinha que mudar a sociedade de Siracusa profundamente.

\section{Considerações Finais}

Espero ter mostrado, que uma análise que aplica o conceito de classe como relação de exploração pode nos ajudar a interpretar uma tradição fragmentária e escassa para chegar a explicações teóricas coerentes de processos político-sociais na antiguidade grega. Enquanto outras perspectivas privilegiam agrupamentos políticos, como frações que lutam pelo poder no estado, a análise de classe, que se baseia em relações socioeconômicas, pode iluminar possíveis causas destes conflitos.

Esta ótica pode também ajudar a compreender melhor outros eventos da história da Sicília grega, como o movimento "autonomista" dos sikelioi liderado por Doukétios. Doukétios criou uma aliança de várias cidades sículanas, lutou contra poderosas poleis gregas e aparentemente gozou do apoio de escravos e servos 
sículanos, criando áreas de refúgio para os escravizados. A literatura que trata deste antigo líder entende a sua luta principalmente em termos étnicos ou políticos, como aquele da autonomia (Jackman, 2006; Hall, 2012, p. 365; Asheri, 2008, p. 161-165; Holloway, 2000, p. 86-87; Berger, 1992, p. 77). Mas etnicidade é uma categoria de alta subjetividade dificilmente estudada em um grupo que não deixou uma tradição própria. Nem sabemos se realmente existia uma identidade sícula ou se este termo foi simplesmente atribuído pelos gregos para denominar um outro bárbaro. A importância da autonomia no outro lado podia ser um reflexo da ideologia política grega que se condensou nas nossas fontes e que considerava a autonomia da polis como um valor principal. Portanto é possivelmente equivocado analisar o movimento de Doukétios a partir da procura por autonomia das cidades sículas. Ambas as perspectivas não parecem descrever muito bem o papel dos escravos neste contexto. Se nós olhamos para o fato, que a escravidão do bárbaro era especialmente justificada pela ideologia dos gregos, o termo do bárbaro ganha um aspecto de classe, e as áreas inabitadas por sikeloi livres precisam ser, na ótica grega, consideradas como reservatórios de escravos potenciais. Desta forma a luta pela "autonomia" das cidades e povoações dos sikeloi e contra a expansiva polis grega, que empenhava a dominação e exploração do campo, pode bem ser caracterizada como uma luta de classe, que tinha o potencial de unir os escravos de fato e os escravos potenciais na base dos seus interesses materiais. A vinculação das contradições entre campo e cidade e entre domínio grego e periferia sículana possibilitavam a confluência destes interesses. Assim o regime de trabalho e as suas relações de exploração, interligadas com as fronteiras étnicas, culturais e políticas da colonização grega, conferiram aos conflitos político-sociais na Sicília oriental do quinto século a.C. a sua forma específica.

Isto, porém, não significa que uma análise de classe é a única abordagem que promete ser frutífera neste campo: As ideias de Homi Bahba sobre tradução e hibridismo (Bahba, 1994, p. 67-82) parecem servir bem para explicar as contradições de um movimento de colonização que legitima a sua dominação através da diferença entre grego e bárbaro, mas, ao mesmo tempo, deteriora esta diferença em moldar os dominados através da sua própria imagem, como é manifesto no processo de helenização. A figura de Doukétios, considerado um sículo helenizado, parece ser um marcante exemplo para este processo: Apesar de dirigir a resistência anti-grega, ele 
também sabia agir perfeitamente no meio político da polis, e, depois de ser derrotado e exilado para a Grécia, voltou como liderança de um novo projeto de colonização formado por ambos gregos e sikelioi.

\section{Fontes}

ARISTÓTELES. 2006. Politik, übersetzt und herausgegeben von Olof Gigon. Ungekürzte Ausgabe nach dem Text der zweiten durchgesehenen Auflage in der "Bibliothek der Alten Welt« des Artemis Verlags. 10 Edição, Zurique e Munique, Dtv, 395 p.

DIODORO. 1998. Griechische Weltgeschrichte, Buch 11-13, übersetzt von O. Veh, eingeleitet und kommentiert von W. Will. Stuttgart, Hiersemann, 388 p.

HERÓDOTO. 2006. Historien, Griechisch-deutsch. 7o Edição, Munique et al., Artemis, $1442 \mathrm{p}$.

SUDA ON LINE: BYZANTINE LEXICOGRAPHY. 2008. s.V. Kallikyrioi. Disponível em: http://www.stoa.org/sol-entries/kappa/255. Acesso em: 25/04/2017.

TUCÍDIDES. 2002. Geschichte des Peloponnesischen Krieges. Herausgegeben und übersetzt von Georg Peter Landmann. Düsseldorf e Zurique, Artemis \& Winkler, 644 p.

\section{Referencias bibliográficas}

ALFÖLDY, G. 2011. Römische Sozialgeschichte. 4o Edição, Stuttgart, Steiner, 399 p.

ANDO, H. 1988. A Study of Servilce Peasantry of Ancient Greece: Centering around Hectemoroi of Athens. In: T. YUGE; M. DOI (org.), Forms of Control and Subordination in Antiquity. Leiden, Brill, p. 323-329.

ASHERI, D. 2008. Sicily, 478-431 B.C. In: D. M. LEWIS et al. (ed.), The Cambridge Ancient History, Vol. II. Cambridge, Cambridge University Press, p. 147-170.

BACKHAUS, W. 1974. Marx, Engels und die Sklaverei. Zur ökonomischen Problematik der Unfreiheit. Düsseldorf, Schwann, 267 p.

BAHBA, H. 1994. The Location of Culture. Routledge, Londres e Nova lorque, 408 p.

BERGER, S. 1992. Revolution and Society in Greek Sicily and Southern Italy. Stuttgart, Steiner, $128 \mathrm{p}$.

BERVE, H. 1953. Zur Herrscherstellung der Deinomeniden. In: G. E. MYLONAS; D. RAYMOND (org.), Studies Presented to David Moore Robinson on His Seventieth Birthday. Saint Louis, Washington University, p. 537-552. 
BLEICKEN, J. 1986. Die athenische Demokratie. Paderborn et al., UTB, 424 p.

BROCKMEYER, N. 1987. Antike Sklaverei. Darmstadt, WBD, 392 p.

CARLÀ, F. 2014. Ein Sklavenaufstand in Syrakus (414 v.Chr.). In: Incidenza dell'Antico. Dialoghi di storia greca, 12, p. 61-89.

DIERSE, U. 1971. s. V. Anarchie, Anarchismus. In: J. RITTER (org.), Historisches Wörterbuch der Philosophie, Völlig neubearbeitete Ausgabe des 'Wörterbuchs der philosophischen Begriffe' von Rudolf Eisler, Vol. I: A-C. Basel, Schwabe, colunas 267-294. DOI, M. 1988. Methods for Viewing World History from the Perspective of the Ruled. In: T. YUGE; M. DOI (org.), Forms of Control and Subordination in Antiquity. Leiden, Brill, p. 3-8.

DUNBABIN, T. J. 1948. The Western Greeks. The History of Sicily and South Italy from the Foundation of the Greek Colonies to 480 B.C. Oxford, Clarendon, 504 p.

ELLMERS, S. 2009. Die formalanalytische Klassentheorie von Karl Marx. Ein Beitrag zur 'neuen Marx-Lektüre'. Duisburg, UVRR, 129 p.

FINLEY, M. I. 1977a. Die Antike Wirtschaft. Munique, Dtv, 219 p.

FINLEY, M. I. 1977b. The Ancient City: From Fustel de Coulanges to Max Weber and Beyond. In: Comparative Studies in Society and History, 19(3), 305-327 p.

FROLOV, E. D. 1995. Gamoroi et Killyrioi. Analyse de la structure sociale et de la lutte sociale dans la Syracuse archaïque. In: M. M. MACTOUX (org.), Esclavage et dépendance dans I'historiographie soviétique récente. Paris, Belles Lettres, p. 73-91.

HALL, J. M. 2012. The Creation and Expression of Identity: The Greek World. In: S. E. ALCOOK, R. OSBORNE, Classical Archaeology. 2o Edição, Chichester e Malden, WileyBlackwell, p. 350-368.

HARRIS, W. V. 1988. On the Applicability of the Concept of Class in Roman History. In: T. YUGE; M. DOI (org.), Forms of Control and Subordination in Antiquity. Leiden, Brill, p. 598-610.

HERRMANN-OTTO, E. 2009. Sklaverei und Freilassung in der griechisch-römischen Welt. Hildesheim, Olms, 263 p.

HOFER, M. 2000. Tyrannen, Aristokraten, Demokraten. Untersuchungen zu Staat und Herrschaft im griechischen Sizilien. Bern, Lang, 293 p.

HOLLOWAY, R. R. 2000. The Archaeology of Ancient Sicily. Londres, Routledge, 232 p.

JACKMAN, T. 2006. Ducetius and Fifth-Century Sicilian Tyranny. In: S. LEWIS, Ancient 
Tyranny. Edinburgh, Edinburgh University Press, p. 33-48.

KIPPENBERG, H. G. 1977. Zur Typik antiker Entwicklung. In: H. G. Kippenberg (org.), Seminar: Die Entstehung der antiken Klassengesellschaft. Francoforte do Meno, Suhrkamp, p. 9-62.

MAEZAWA, N. 1988. Slave Societies in the Greco-Roman Antiquity. In: T. YUGE; M. DOI (org.), Forms of Control and Subordination in Antiquity. Leiden, Brill, p. 16-18.

MANISCALCO, L.; McCONNEL, B. E. 2003. The Sanctuary of the Divine Palikoi (Rocchicella di Mineo, Sicily): Fieldwork from 1995 to 2001. In: American Journal of Archaeology, 107(2), p. 145-180.

MARX, K. 1972. Zur Kritik der Hegelschen Rechtsphilosophie. In: INSTITUT FÜR MARXISMUS-LENINISMUS (org.), Marx-Engels-Werke, Vol I. Berlin, Dietz, p. 378-391.

NIPPEL, W. 1984. The Class Struggle in the Ancient Greek World from the Archaic Age to the Arab Conquests by G. E. M. De Ste. Croix. In: Gnomon, 56(8), p. 623-633.

STARR, C. G. 1977. The Economic and Social Growth of Early Greece 800-500 BC. New York, Oxford University Press, $267 \mathrm{p}$.

STE. CROIX, G. E. M. DE. 1981. The Class Struggle in the Ancient Greek World: from the archaic age to the Arab conquests. Ithaca e Nova Yorque, Cornell University Press, 732 p.

STEINER, H. 2008. s. V. Klassenanalyse. In: W. F. HAUG; F. HAUG, Historisch-Kritisches Wörterbuch des Marxismus, Vol. 7/I. Hamburgo, Argument, p. 776-786.

VYSOKIJ, M. F. 2002. Migration in the archaic Sicily. In: E. OLSHAUSEN; H. SONNABEND, Trojaner sind wir gewesen. Stuttgart, Franz Steiner Verlag, p. 250-256.

WEBER, M. 1980. Wirtschaft und Gesellschaft. Grundriss der verstehenden Soziologie. 5을 Edição, Tübingen, J.C.B. Mohr, 945 p.

WENTKER, H. 1956. Sizilien und Athen. Die Begegnung der attischen Macht mit den Westgriechen. Heidelberg, Quelle \& Meyer, 197 p.

Artigo recebido em 13 de maio de 2017 e aprovado em 04 de junho de 2017. 